\title{
Congenital enteropathy due to enteropeptidase deficiency
}

INSERM

\section{Source}

INSERM. (1999). Orphanet: an online rare disease and orphan drug data base. Congenital enteropathy due to enteropeptidase deficiency. ORPHA:168601

Cong enital enteropathy due to enteropeptidase deficiency is a rare, genetic, gastroenterological disease characterized by early-onset failure to thrive, edema, hypoproteinemia, diarrhea and fat malabsorption (or steatorrhea) in the presence of very low or absent trypsin activity in duodenal fluid. Celiac disease, or other pancreatic or mucosal disorders, may be associated. 